\title{
Autologous Anti-gp100:154-162 T-Cell Receptor Gene-Engineered Peripheral Blood Lymphocytes
}

National Cancer Institute

\section{Source}

National Cancer Institute. Autologous Anti-gp100:154-162 T-Cell Receptor Gene-

Engineered Peripheral Blood Lymphocytes. NCI Thesaurus. Code C71748.

Human autologous peripheral blood lymphocytes (PBLs) transduced with a glycoprotein 100 (gp100) epitope-determined T cell receptor (T CR) gene, with potential antineoplastic activity. PBLs are isolated from a melanoma patient and pulsed with a viral vector encoding the TCR specific for amino acid residues 154-162 of gp100 (KTWGQYWQV). After expansion ex vivo, the transduced autologous PBLs, expressing this specific TCR, are reintroduced into the patient and bind to melanoma cells expressing the gp100 protein, which may result in specific cytotoxic T-lymphocyte (CTL) killing of gp100expressing melanoma cells. gp100 is a melanocyte lineage-specific antigen overexpressed in melanomas. 